\title{
Estimativa de área foliar por meio de relações alométricas em Aechmea blanchetiana (Baker) L. B. SM sob distintas condições de luminosidade
}

\author{
Daniele Freisleben Lavanhole', Pablo Souto Oliveira ${ }^{2}$, Edney Leandro da Vitória ${ }^{3}$ \\ \&. Elisa Mitsuko Aoyama ${ }^{3}$
}

\begin{abstract}
'Universidade Federal do Espírito Santo campus São Mateus, Programa de Pós-Graduação em Agricultura Tropical, Rodovia BR 101 Norte, KM 60, Bairro Litorâneo, São Mateus, Espírito Santo, Brasil danieleflavanhole@hotmail.com 2Universidade Federal do Espírito Santo campus São Mateus, Rodovia BR 101 Norte, KM 60, Bairro Litorâneo, São Mateus, Espírito Santo, Brasil pablosoutol3@hotmail.com

${ }^{3}$ Universidade Federal do Espírito Santo campus São Mateus, Departamento de Ciências Agrárias e Biológicas, Rodovia, BR 101 Norte, Km 60, Bairro Litorâneo, CEP 29932-540, São Mateus, Espírito Santo, Brasil vitoria@ufes.br, elisaoyama@yahoo.com.br
\end{abstract}

Recebido em 13.11.2016

Aceito em 06.XI.2018

DOI 10.21826/2446-8231201873313

\begin{abstract}
RESUMO - O objetivo do estudo foi determinar o modelo de regressão adequado para estimar a área foliar, utilizando relações alométricas das folhas de Aechmea blanchetiana (Baker) L. B. SM. A investigação foi conduzida em três áreas de restinga no município de São Mateus, Espírito Santo onde foram selecionados pontos aleatórios, coletando-se cinco folhas de cada indivíduo, totalizando 500 folhas. Análises de regressão linear e de correlação foram utilizadas nas análises. As folhas sob baixa irradiação apresentaram os maiores valores em todos os parâmetros, exceto pela largura que foi maior em folhas sob alta irradiação. As equações de regressão quando relacionadas com o comprimento e o produto do comprimento vezes a máxima largura mostraram-se as mais adequadas para folhas sob alta irradiação, sendo o produto o mais satisfatório com a equação potencial $\hat{Y}$ $=1,3299 \mathrm{x}^{0,9165}$. Para folhas sob baixa irradiação apenas o produto comprimento vezes a máxima largura foi apropriado, em que a equação potencial $\hat{Y}=0,2454 x^{1,2006}$.
\end{abstract}

Palavras-chaves: área foliar, radiação solar, restinga

ABSTRACT - Estimation of leaf area through allometric relationships in Aechmea blanchetiana (Baker) L. B. SM under different light conditions. The aim of the study was to determine the appropriate regression model to estimate leaf area using allometric relationships of Aechmea blanchetiana (Baker) L. B. Sm. The investigation was conducted in three areas of sandbank in São Mateus, Espírito Santo, where random points were selected, collecting five leaves from each individual, totaling 500 sheets. Linear regression and correlation analysis were used in the analyzes. The leaves under low light have the highest values for all parameters, except for the width, which was higher in leaves under bright light. The regression equations, when related to the length and the product of length, times the maximum width proved to be the most suitable for leaf under bright light, being the product most suitable with the potential equation $\hat{Y}=1,3299 \times 0,9165$. For leaves under low light, only the length of the product times the maximum width is appropriate in the equation $\hat{Y}=0,2454 \times 1,2006$.

Keywords: leaf area, solar radiation, restinga

\section{INTRODUÇÃO}

Aechmea blanchetiana é uma espécie endêmica do Brasil, de hábito herbáceo típica do ecossistema de restinga, suas folhas se dispõe em forma de roseta formando tanques (Forzza et al. 2015), no qual, propicia um micro-habitat para vários organismos. É caracterizada por suas grandes touceiras com folhagem de coloração amarelada quando em alta irradiação, ou verde escuro quando em baixa irradiação (Kanashiro et al., 2007).

No estado do Espírito Santo a família Bromeliaceae é uma das mais ricas em espécies, dentre elas, $A$. blanchetiana apresenta o maior número de indivíduos, maior frequência e valor de importância (Monteiro et al. 2014). No entanto, sua ampla distribuição entre os estados do Espírito Santo e
Bahia (Gomes \& Silva 2013) vem sofrendo com a grande ação antrópica, ocasionando a perda e fragmentação de habitats (Martilelli \& Moraes 2013), comprometendo toda a biodiversidade existente nesse ambiente.

As espécies vegetais possuem diferentes exigências para sua sobrevivência, sendo a luminosidade um dos principais fatores para o seu crescimento, por influir entre outros processos, na taxa de fotossíntese. Tanto a quantidade como a qualidade de luz é importante para muitos processos fisiológicos nos vegetais, como o fotoperiodismo e fototropismo (Poggiani et al. 1992). Dependendo da captura e capacidade de uso de irradiância, plantas apresentam diferentes respostas decisivas para a sua sobrevivência, crescimento e adaptação sob diferentes condições de luz. A capacidade das plantas em ajustar seu metabolismo para 
otimizar a utilização de recursos primários, como a luz irá determinar o sucesso ou o fracasso de sua adaptação e estabelecimento em determinadas condições de irradiância (Gonçalves et al. 2007).

Entre as formas de se avaliar as respostas das plantas as diferentes condições ambientais estão à área folia, que é utilizada principalmente para avaliar o crescimento dos vegetais, devido ser o aparato de intercepção de luz para a fotossíntese. A folha é o principal órgão no processo transpiratório, responsável pelas trocas gasosas entre a planta e o ambiente (Pereira et al. 1997), razão pela qual o conhecimento da superfície foliar é de grande utilidade para a avaliação de outras técnicas culturais (Lucena et al. 2011).

De acordo com Mendonça et al. (2007) a área foliar é utilizada principalmente para analisar o crescimento e estudos de fenologia e nutrição da planta, o que segundo Fonseca \& Condé (1994) constataram que a partir da estimativa da área foliar é possível chegar a algumas variáveis ecofisiológicas como área foliar específica, razão de área foliar, índice de área foliar, taxa assimilatória líquida, taxa de crescimento foliar relativo, entre outras que permitem inferir sobre a eficiência fotossintética, padrões de crescimento e desenvolvimento e quantificação de variações no crescimento das plantas devido a diferenças genéticas ou ambientais.

Diversas são as formas de se medir a área foliar, porém muitas são inadequadas por serem destrutivas ou por dependerem de aparelhos disponíveis somente em laboratórios ou, ainda, por demandarem de excessiva mãode-obra para execução (Lucena et al. 2011). Conforme Francisco et al. (2014) esta pode ser realizada por meio de instrumentos de medição (métodos destrutivos) ou por modelos de regressão (métodos não destrutivos).

Os métodos destrutivos têm a desvantagem de não serem aplicáveis em casos onde a quantidade de amostras é limitada e/ou quando se pretende manter a avaliação de outros parâmetros em experimentos por um longo período de tempo, o que impossibilita a destruição das unidades experimentais ou parcelas para a realização de medidas diretas da área foliar (Schwab et al. 2014). Já o método não-destrutivo permite acompanhar o crescimento e a expansão foliar da mesma planta até o final do ciclo ou do ensaio, além de ser rápido e preciso. Assim, a área foliar pode ser estimada utilizando-se parâmetros dimensionais de folhas, os quais apresentam boas correlações com a superfície foliar. Um dos métodos não-destrutivos mais utilizados é a estimativa da área foliar por meio de equações de regressão entre a área foliar real $(\mathrm{Sf})$ e os parâmetros dimensionais lineares das folhas (Bianco et al. 2002).

Segundo Pinto et al. (2008) a adoção de equações matemáticas ou modelos de regressões para estimativa da área foliar torna-se uma alternativa não-destrutiva simples, rápida, confiável e barata. Assim, a estimativa da área foliar utilizando a relação entre as dimensões lineares da folha e a respectiva área destaca-se como alternativa simples, barata e acessível, necessitando apenas de régua e cálculos associados. Nesses modelos, o procedimento mais utilizado para a estimar a área foliar consiste na determinação das dimensões lineares, envolvendo medidas de comprimento, largura e área foliar de amostras de folhas (Araujo et al. 2005) afim de ajustar equações de regressão e escolher as que apresentam melhor precisão estatística para estimar $\mathrm{a}$ área de amostras subsequentes (Francisco et al. 2014).

Estudos para determinação da estimativa de área foliar em espécies da família Bromeliaceae são raros, no entanto, se faz necessário, visto que suas espécies são de grande valor ecológico, além do potencial ornamental. Em especial Aechmea blanchetiana é uma espécie com ampla distribuição na restinga do litoral do Espírito Santo, porém, este vem sofrendo constantemente com ações antrópicas, o que acarreta na perda e fragmentação do habitat desta espécie. Estudos da estimativa de área foliar são essências para averiguar a relação da espécie com o ambiente ao qual esta inserida.

\section{MATERIAL E MÉTODOS}

Os indivíduos de A. blanchetiana (Figs. 1 A, B) foram amostrados em três áreas na restinga do município de São Mateus-ES, sendo respectivamente: área 1 (azul) (Fig. 2 C)
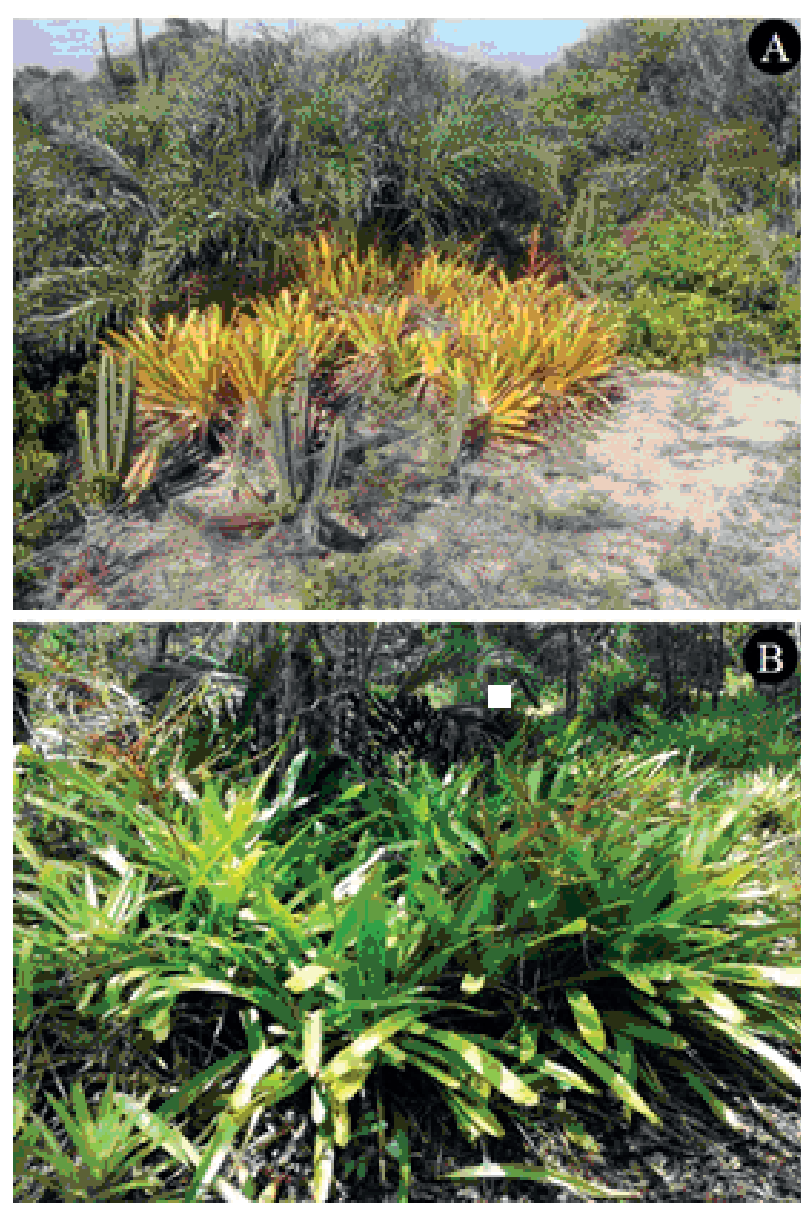

Figs. 1A, B. Indivíduos adultos de Aechmea blanchetiana (Baker) L. B. Sm. A. Indivíduos sob alta irradiação. B. Indivíduos sob baixa irradiação. 
bairro Liberdade; área 2 (vermelho) (Fig. 2 C), bairro Guriri Sul e área 3 (verde) (Fig. 2 C), bairro Barra Nova. Nas áreas 1 (Fig. 2 D) e 3 (Fig. 2 F) foram amostrados quatro pontos, em que dois pontos são sob alta irradiação solar e dois sob baixa irradiação solar. Na área 2 (Fig. 2 E) foram amostrados oito pontos, quatro sob alta irradiação e quatro sob baixa irradiação. Para a coleta das folhas padronizou-se indivíduos com tamanhos aproximados, para não interferir nos dados. O material botânico fértil de cada área foi depositado no herbário da Universidade Federal do Espírito Santo (UFES), com os respectivos número de voucher 36231,36232 . Todos os pontos amostrados foram georreferenciados por meio de GPS de marca Garmin Etrex Legend.
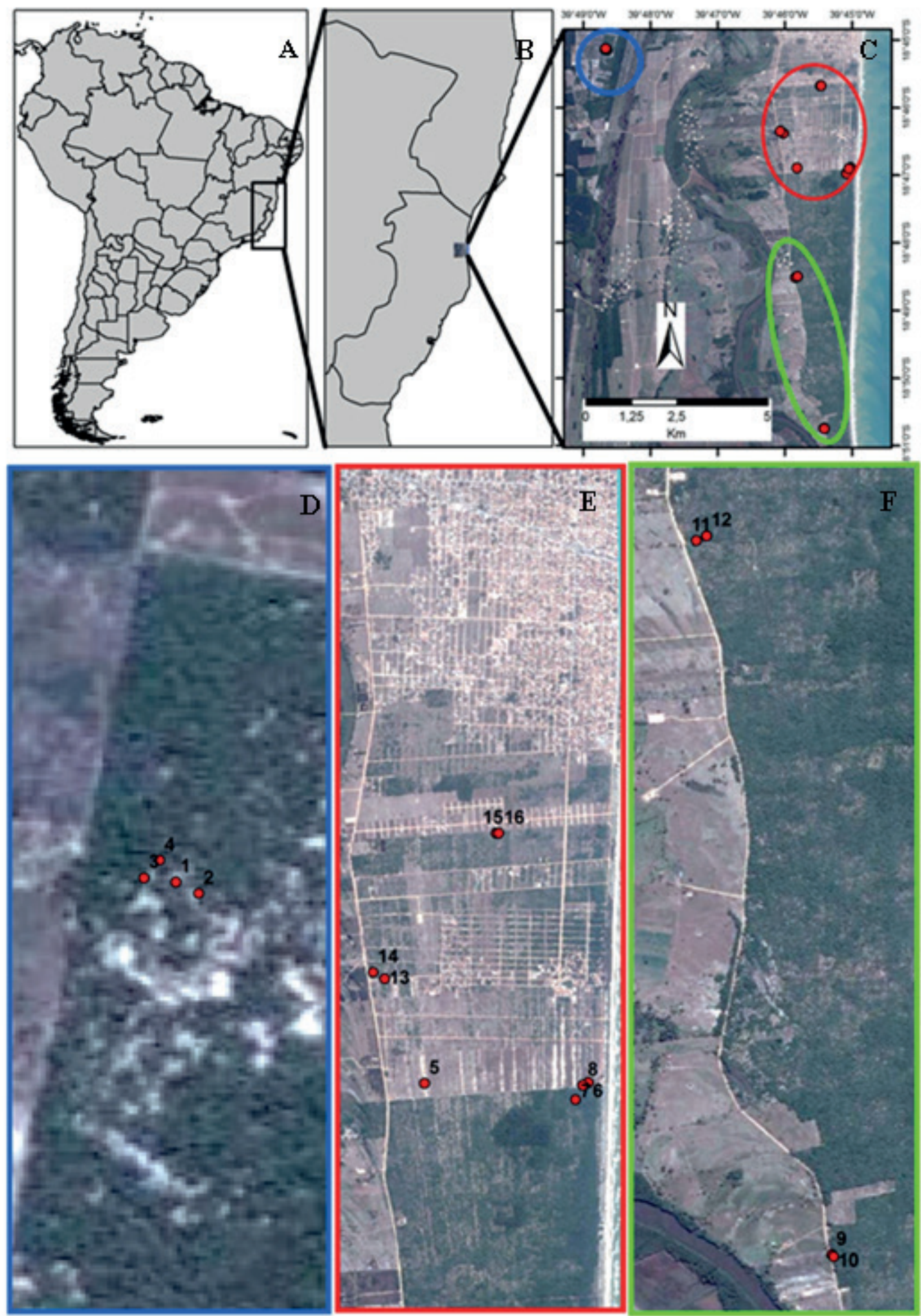

Figs. 2A-F. Mapas dos pontos geográficos. A. Mapa do Brasil, em destaque o estado do Espírito Santo; B. Mapa do estado do Espírito Santo, em destaque o município de São Mateus; C. Áreas de coletas (1- Bairro Liberdade, 2- Bairro Guriri Sul, 3- Bairro Barra Nova); D. Pontos de coletas do bairro Liberdade; E. Pontos de coletas do bairro Guriri-Sul; F. Pontos de coletas no bairro Barra Nova. 
Segundo classificação de Köppen o clima do município de São Mateus é Aw, caracterizado por clima tropical úmido, com inverno seco e chuvas máximas no verão. A precipitação pluvial anual média de $1.200 \mathrm{~mm}$ concentrase entre os meses de novembro e janeiro. A temperatura média anual é de $23^{\circ} \mathrm{C}$, e as médias máximas e mínimas são de $29^{\circ} \mathrm{C} \mathrm{e} 18^{\circ} \mathrm{C}$, respectivamente (Kottek et al. 2006).

As medidas de intensidade luminosa foram tomadas por meio de um luxímetro digital marca LI-COR Model LI-250 light meter, posicionado horizontalmente acima dos indivíduos em 10 pontos diferentes de cada ponto.

\section{Área foliar}

Foi estimada por uma amostra de 100 indivíduos localizados sob alta irradiação e 100 localizados sob baixa irradiação. De cada indivíduo foram selecionadas 5 folhas aleatórias totalmente expandidas da periferia da roseta, totalizando 500 folhas de indivíduos sob alta irradiação e 500 folhas de indivíduos sob baixa irradiação.

As medições das folhas foram realizadas com auxílio de trena milimétrica (Fig. 3. A) relativa às maiores larguras $(\mathrm{L}, \mathrm{em} \mathrm{cm})$, na posição mediana do limbo, bem como os comprimentos $(\mathrm{C}$, em $\mathrm{cm})$, além disso, calculou-se o produto entre comprimento e largura (C.L).

Posteriormente, com auxílio de um calador com diâmetro de 3,4 cm, recortaram-se três discos (Figs. $3 \mathrm{~B}$, C), um da região do ápice, da mediana e da base de cada folha, incluindo as nervuras.

As amostras dos discos foliares e o restante de cada folha amostrada foram acondicionados separadamente em sacos de papel e levados à estufa de secagem, com aeração forçada e temperatura de $65{ }^{\circ} \mathrm{C}$, por 6 dias, até massa constante. A massa de matéria seca (Fig. 3 E) das duas partes foi determinada com auxílio de uma balança eletrônica com precisão de $0,01 \mathrm{~g}$, marca Shimadzu, modelo BL3200H. A área total de cada folha $\mathrm{em}\left(\mathrm{cm}^{2}\right)$ foi calculada por meio da expressão:

$$
\mathrm{AF}=\frac{M S T \times A T D}{M S D}
$$

Em que MST é a massa seca total das folhas, ATD é área total dos discos e MSD é a massa seca dos discos. Em seguida, foram calculadas medidas de tendência central, variabilidade, e verificada a normalidade para as variáveis C, L, C.L e AFO, pelo teste de Shapiro-Wilk (Campos 1983, Zar 2010, Schmildt et al. 2014).

Para modelar a AFO (variável dependente $=\mathrm{Y}_{\mathrm{i}}$ ) em função do C, da L ou do C.L das 500 folhas como variáveis independentes $\left(\mathrm{x}_{\mathrm{i}}\right)$ foram utilizadas os seguintes modelos: linear simples $\left(\mathrm{Y}_{\mathrm{i}}=\beta_{0}+\beta_{1} \mathrm{x}_{\mathrm{i}}+\mathrm{e}_{\mathrm{i}}\right)$, exponencial $\left(\mathrm{Y}_{\mathrm{i}}=\beta_{0} \beta_{1}{ }^{\mathrm{xi}}+\mathrm{e}_{\mathrm{i}}\right)$, polinomial quadrático $\left(\mathrm{Y}_{\mathrm{i}}=\beta_{0}+\beta_{1} \mathrm{X}_{\mathrm{i}}+\right.$ $\left.\beta_{2} \mathrm{x}_{\mathrm{i}}^{2}+\mathrm{e}_{\mathrm{i}}\right)$ e potencial $\left(\mathrm{Y}_{\mathrm{i}}=\beta 0 \mathrm{xi}^{\beta 1}+\mathrm{e}_{\mathrm{i}}\right)$, e seus respectivos coeficientes de determinação $\left(\mathrm{R}^{2}\right)$. Os parâmetros $\beta_{0}$ e $\beta_{1}$ foram estimados pelo método dos mínimos quadrados tendo sido feita previamente a linearização das funções potencial e exponencial.
A validação dos modelos de estimativa de área foliar foi realizada com base nos valores estimados pelo modelo $\left(\hat{Y}_{i}\right)$ e os valores observados $\left(\mathrm{Y}_{\mathrm{i}}\right)$ em 100 folhas. Em cada modelo, inicialmente, foi ajustada uma regressão linear simples $\left(\hat{Y}_{\mathrm{i}}=\beta_{0}+\beta_{1} \mathrm{X}_{\mathrm{i}}\right)$ da área foliar estimada pelo modelo (variável dependente) em função da área foliar observada (variável independente).

Foram testadas as hipóteses $\mathrm{H}_{0}: \beta_{0}=$ versus $\mathrm{H}_{\mathrm{a}}: \beta_{0} \neq 0$ e $\mathrm{H}_{0}: \beta_{1}=1$ versus $\mathrm{H}_{\mathrm{a}}: \beta_{1} \neq 1$, por meio do teste $\mathrm{t}$ de Student a $5 \%$ de probabilidade. Determinou-se também o erro médio ( $\overline{\mathrm{E}})$, erro absoluto médio (EAM), a raiz do quadrado médio do erro (RQME) e o índice de Willmott (d) (Willmott 1981, Schmildt et al. 2014), para todas as equações por meio, das expressões:

$$
\begin{gathered}
\bar{E}=\frac{\sum_{\mathrm{i}=1}^{n}\left(\hat{Y}_{i}-Y_{i}\right)}{n} ; \\
\mathrm{EAM}=\frac{\sum_{\mathrm{i}=1}^{\mathrm{n}}\left|\hat{\mathrm{Y}}_{\mathrm{i}}-\mathrm{Y}_{\mathrm{i}}\right|}{\mathrm{n}} ; \\
\mathrm{RQME}=\sqrt{\frac{\sum_{\mathrm{i}=1}^{\mathrm{n}}\left(\hat{\mathrm{Y}}_{\mathrm{i}}-\mathrm{Y}_{\mathrm{i}}\right)^{2}}{\mathrm{n}} ;} \\
\mathrm{d}=1-\left[\frac{\sum_{\mathrm{i}=1}^{\mathrm{n}}\left(\hat{\mathrm{Y}}_{\mathrm{i}}-\mathrm{Y}_{\mathrm{i}}\right)^{2}}{\sum_{\mathrm{i}=1}^{\mathrm{n}}\left(\left|\hat{\mathrm{Y}}_{\mathrm{i}}-\overline{\mathrm{Y}}\right|+\left|\mathrm{Y}_{\mathrm{i}}-\overline{\mathrm{Y}}\right|\right)^{2}}\right]
\end{gathered}
$$

Em que: $\hat{Y}_{i}$ são os valores estimados de área foliar;são os valores observados de área Foliar; $\bar{Y}$ é a média dos valores observados; $\mathrm{n}$ é o número de folhas.

\section{Análises Estatísticas}

Dados de comprimento e largura da folha, massa fresca e seca e pigmentos foram submetidos à análise de estatística descritiva para resultados de média e desvio padrão. Os dados foram submetidos à análise de variância (ANOVA) em experimento inteiramente casualizado, posteriormente passaram pelo teste de normalidade. Para os dados não paramétricos foi utilizado o teste Shapiro-Wilk para a normalização, utilizando a fórmula $x=\sqrt{x}$, em seguida o teste de Tukey $(\mathrm{p} \leq 0,05)$ para a comparação de médias utilizando o programa estatístico Assistat Versão 7.7 beta (Silva \& Azevedo 2009).

\section{RESULTADOS E DISCUSSÃO}

A intensidade luminosa foi maior sob alta irradiação com média de 2202,78Lux $\pm 307,02$ e 64,62Lux $\pm 26,33$ sob baixa irradiação.

Suas folhas apresentaram diferenças estatisticamente significativas quanto ao comprimento (C) e largura (L), 

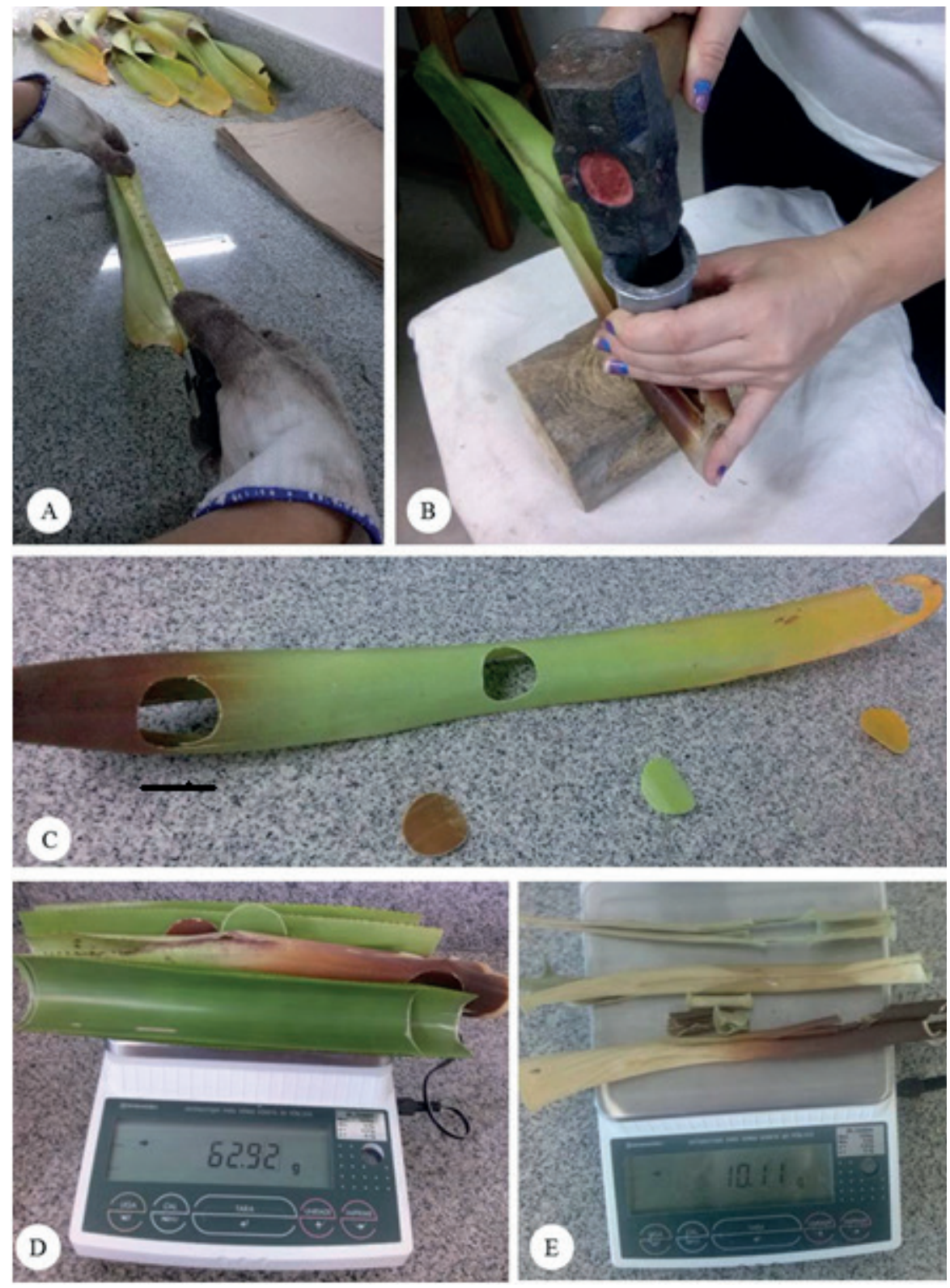

Figs. 3A-E. Análise de área foliar das amostras coletadas de Aechmea blanchetiana (Baker) L. B. Sm. A. Mensuração da folha; B. Retirada do disco; C. Diferentes posições de retirada dos discos na folha; D. Pesagem de folhas frescas sob baixa irradiação; E. Pesagem de folhas secas sob baixa irradiação sendo pesada. Barra $=40 \mathrm{~mm}$.

conforme intensidade luminosa a qual está submetida. As folhas sob alta irradiação apresentaram menor comprimento (C) e maior largura foliar (Tab. 1) quando comparadas as folhas sob baixa irradiação. Diante do exposto, acredita-se que o menor comprimento e a maior largura em folhas sob alta irradiação, seja uma forma de minimizar a alta irradiação sob a superfície foliar, enquanto o maior comprimento e menor largura em folhas sob baixa irradiação esteja associado como uma melhor forma para a captação da luz. De acordo com Falster \& Westoby (2003) o maior benefício de folhas com um menor tamanho é a habilidade para uma rápida dissipação de calor por convecção, o que faz com que estas folhas não superaqueçam com a temperatura do ar, o que segundo Sabbi et al. (2010) favorece para uma diminuição da transpiração.

Estudos realizados com Aechmea lindenii (E. Morren) Baker por Lenzi et al. (2006) e Voltolini \& Santos (2011) apresentaram resultados semelhantes ao encontrado neste trabalho, onde folhas sob alta irradiação apresentaram menor comprimento e maior largura quando comparadas com folhas sob baixa irradiação solar.

As folhas dos indivíduos sob alta irradiação apresentaram uma considerável variação para comprimento (C) mínimo, comprimento vezes a largura (C.L) mínima e máxima e área foliar observada (AFO) mínima e máxima, sendo esta variação menor nas folhas usadas na obtenção das equações (amostras de 500 folhas) em relação às folhas usadas na 
validação dos modelos (amostra de 100 folhas) (Tab. 1), no entanto as folhas sob baixa irradiação usadas na obtenção das equações (amostras de 500 folhas), quanto às folhas usadas na validação dos modelos (amostras de 100 folhas), não apresentaram uma variação considerável em relação ao comprimento $(\mathrm{C})$ mínimo, comprimento vezes a largura (C.L) mínima e área foliar observada (AFO) mínima, apenas variaram em relação ao comprimento $(\mathrm{C})$ máximo e comprimento vezes a largura máxima (C.L) (Tab. 1).

A maior variação nos parâmetros das folhas sob alta irradiação pode estar relacionado com a grande variação de radiação solar em que as mesmas se encontram, enquanto que a menor variação nos parâmetros nas folhas sob baixa irradiação deve se ao fato de estarem em um ambiente com uma menor variação da radiação. De acordo com Campos \& Uchida (2002) a expansão da folha sob baixa luminosidade é relatada frequentemente e indica a maneira da planta em compensar a menor quantidade de luz recebida, aproveitando-a para processos fisiológicos relativos ao seu crescimento.

Sabbi et al. (2010) avaliando caracteres morfoanatômicos e fisiológicos de Schinus terebinthifolius Raddi (Anacardiaceae) em área aberta e em capoeira, obtiveram maior área foliar em indivíduos de capoeira o que se assemelharia aos indivíduos sob baixa luminosidade do presente estudo, enquanto que Vieira (2013) em floresta ombrófila densa avaliando a plasticidade fenotípica e aclimatação de Siparuna guianensis Aubulet (Siparunaceae) observaram que esta é uma espécie tolerante a sombra e que seu desempenho metabólico é favorecido pelo aumento na disponibilidade de luz. Desta forma podem-se observar as plantas possuem diferentes respostas ao ambiente.

As equações de regressão estimadas são apresentadas na Tabela 2 para indivíduos sob alta irradiação e na Tabela. 3 para indivíduo sob baixa irradiação. Das equações ajustadas para indivíduos sob alta irradiação as que se mostraram estatisticamente significativas foram as que apresentaram coeficiente de determinação superior a 0,7484 (Tab. 2), quando se usou o produto comprimento vezes a máxima largura (C.L) como variável independente no modelo linear, exponencial, quadrático e potencial. Das 12 equações avaliadas, quatro são apropriadas, sendo respectivamente: Potencial (Fig. 4 D), Exponencial (Fig. 4 B), Quadrático (Fig. 4 C) e Linear (Fig. 4 A).

Para as folhas sob baixa irradiação o coeficiente de determinação também foi maior quando se utilizou o produto do comprimento vezes a largura como variável independente, em que $\mathrm{R}^{2}$ foi superior a 0,7063 (Tab. 3). Das 12 equações avaliadas, quatro são apropriadas, sendo respectivamente: Potencial (Fig. 5 D), Exponencial (Fig. 5 B), Quadrático (Fig. 5 C) e Linear (Fig. 5 A).

$\mathrm{O}$ fato em que o produto do comprimento vezes a maior largura ser o mais significativo está relacionado com o formato lanceolado da folha, visto que a discrepância que há entre o comprimento e a largura ser minimizado quando se utiliza os dois parâmetros ao invés de somente um, o mesmo foi observado por Francisco et al. (2014)
Tabela 1. Mínimo, máximo, média e coeficiente de variação $(\mathrm{CV}$, em $\%$ ) do comprimento $\left(\mathrm{C}\right.$, em $\left.\mathrm{cm}^{2}\right)$, maior largura $\left(\mathrm{L}, \mathrm{em}^{2}\right)$ e produto comprimento vezes a maior largura $\left(\mathrm{C} . \mathrm{L}, \mathrm{em} \mathrm{cm}^{2}\right)$ do limbo foliar e da área foliar observada (AFO, em $\mathrm{cm}^{2}$ ) de amostras de Aechmea blanchetiana (Baker) L. B. Sm.m em distintas condições

\begin{tabular}{|c|c|c|c|c|}
\hline & Mínimo & Máximo & Média & $\mathrm{CV}$ \\
\hline \multicolumn{5}{|c|}{$\begin{array}{c}\text { Amostra de } 500 \text { folhas sob alta irradiação para obtenção } \\
\text { das equações de estimativa }\end{array}$} \\
\hline $\mathrm{C}$ & 30,6 & 80,4 & 56,6 & 16,1 \\
\hline $\mathrm{L}$ & 5,1 & 12,0 & 7,8 & 15,4 \\
\hline C.L & 183,6 & 805,6 & 449,5 & 24,4 \\
\hline $\mathrm{AFO}$ & 155,0 & 661,9 & 360,7 & 25,8 \\
\hline
\end{tabular}

Amostra de 100 folhas sob alta irradiação para validação dos modelos

\begin{tabular}{lcccc}
\hline C & 37,9 & 80,4 & 62,3 & 15,5 \\
L & 5,3 & 12 & 7,8 & 17,4 \\
C.L & 276,6 & 754,4 & 482,6 & 19,0 \\
AFO & 172,3 & 653,8 & 383,8 & 26,5 \\
\hline
\end{tabular}

Amostra de 500 folhas sob baixa irradiação para obtenção das equações de estimativa

\begin{tabular}{lcccc}
\hline C & 48,9 & 184,8 & 113,0 & 22,2 \\
L & 4,3 & 9,3 & 6,5 & 13,0 \\
C.L & 298,2 & 1085,4 & 733,3 & 20,0 \\
AFO & 154,9 & 1511,8 & 686,7 & 29,4 \\
\hline \multicolumn{4}{c}{ Amostra de 100 folhas sob baixa irradiação para validação } \\
\multicolumn{4}{c}{ C dos modelos } \\
L & 48,9 & 176,9 & 112,2 & 24,4 \\
C.L & 4,9 & 8,0 & 6,4 & 10,3 \\
AFO & 298,2 & 1053,9 & 723,3 & 24,6 \\
\hline
\end{tabular}

Tabela 2. Equações para a determinação da área foliar, utilizando o comprimento (C), a largura (L) e o produto comprimento vezes a largura (C.L) como variáveis independentes $(x)$ e coeficiente de determinação $\left(\mathrm{R}^{2}\right)$, com base em 500 folhas sob alta irradiação de Aechmea blanchetiana (Baker) L. B. Sm. Os índices 1, 2 e 3 indicam comprimento, largura, comprimento x largura, respectivamente.

\begin{tabular}{lccc}
\hline Modelo & X & Equação & $\mathrm{R}^{2}$ \\
\hline Linear 2 & $\mathrm{L}$ & $\hat{\mathrm{Y}}=43,328 \mathrm{x}+18,967$ & 0,3196 \\
Linear 3 & C.L & $\hat{\mathrm{Y}}=0,7349 \mathrm{x}+30,392$ & 0,7484 \\
Exponencial 1 & C & $\hat{\mathrm{Y}}=93,781(1,023)^{\mathrm{x}}$ & 0,6467 \\
Exponencial 2 & $\mathrm{L}$ & $\hat{\mathrm{Y}}=137,32(1,136)^{\mathrm{x}}$ & 0,3503 \\
Exponencial 3 & C.L & $\hat{\mathrm{Y}}=136,13(1,002)^{\mathrm{x}}$ & 0,7654 \\
Quadrático 1 & C & $\hat{\mathrm{Y}}=0,0295 \times 2+4,6544 \mathrm{x}$ & 0,6337 \\
Quadrático 2 & $\mathrm{L}$ & $\hat{\mathrm{Y}}=-0,4011 \times 2+49,691 \mathrm{x}-5,6669$ & 0,3196 \\
Quadrático 3 & C.L & $\hat{\mathrm{Y}}=-0,0002 \times 2+0,883 \mathrm{x}-2,042$ & 0,7493 \\
Potencial 1 & C & $\hat{\mathrm{Y}}=1,8101 \mathrm{x}^{1,3075}$ & 0,6608 \\
Potencial 2 & $\mathrm{L}$ & $\hat{\mathrm{Y}}=45,242 \mathrm{x}^{0,9947}$ & 0,3558 \\
Potencial 3 & C.L & $\hat{\mathrm{Y}}=1,3299 \mathrm{x}^{0,9165}$ & 0,791 \\
\hline
\end{tabular}



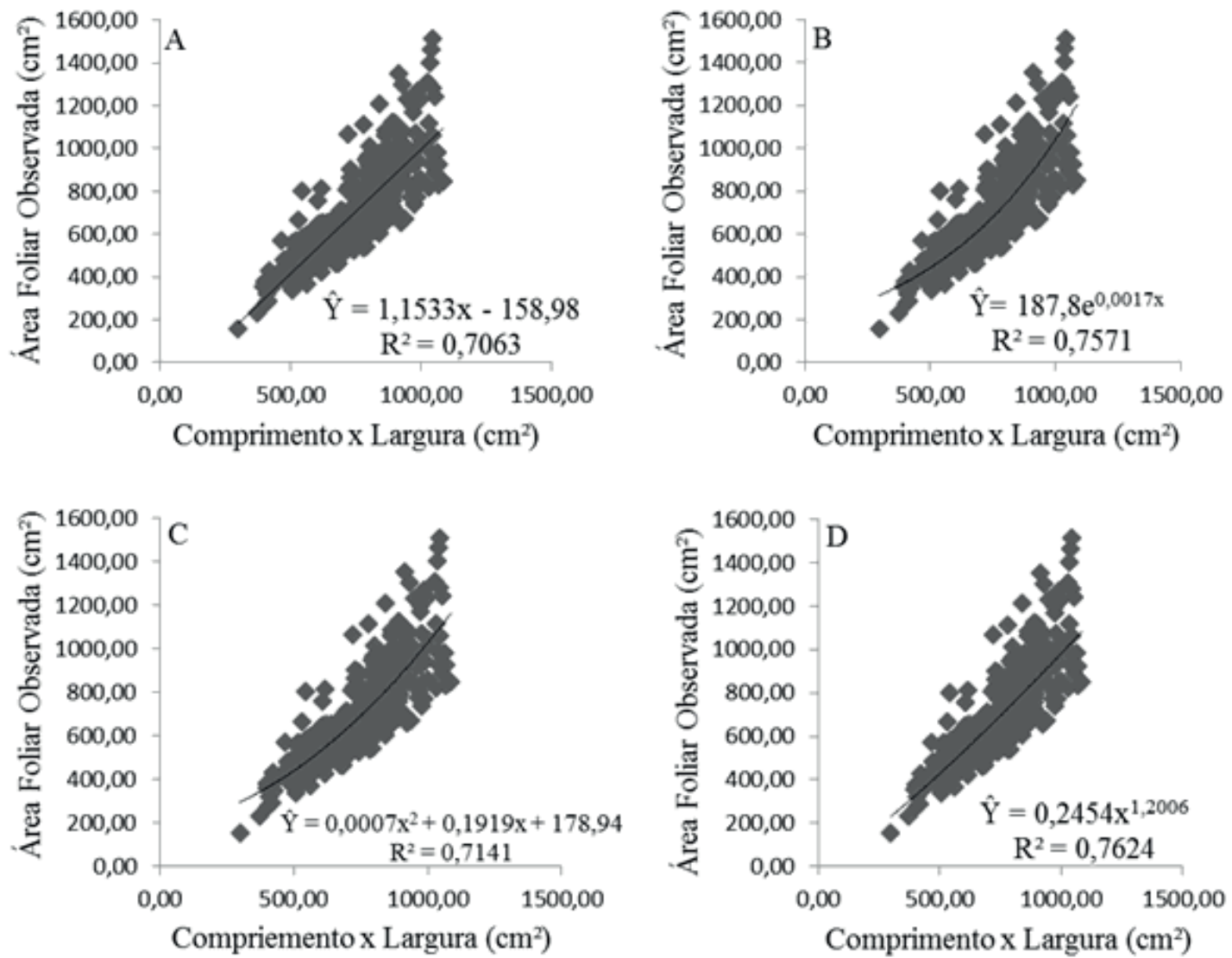

Figs. 4A-D. Representação da área foliar de indivíduos sob alta irradiação de Aechmea blanchetiana (Baker) L. B. Sm. A. modelo Linear; B. Exponencial; C. Quadrático; D. Potencial para o produto entre comprimento e máxima largura (C.L) de folhas. Equações estimadas a partir de 500 folhas.
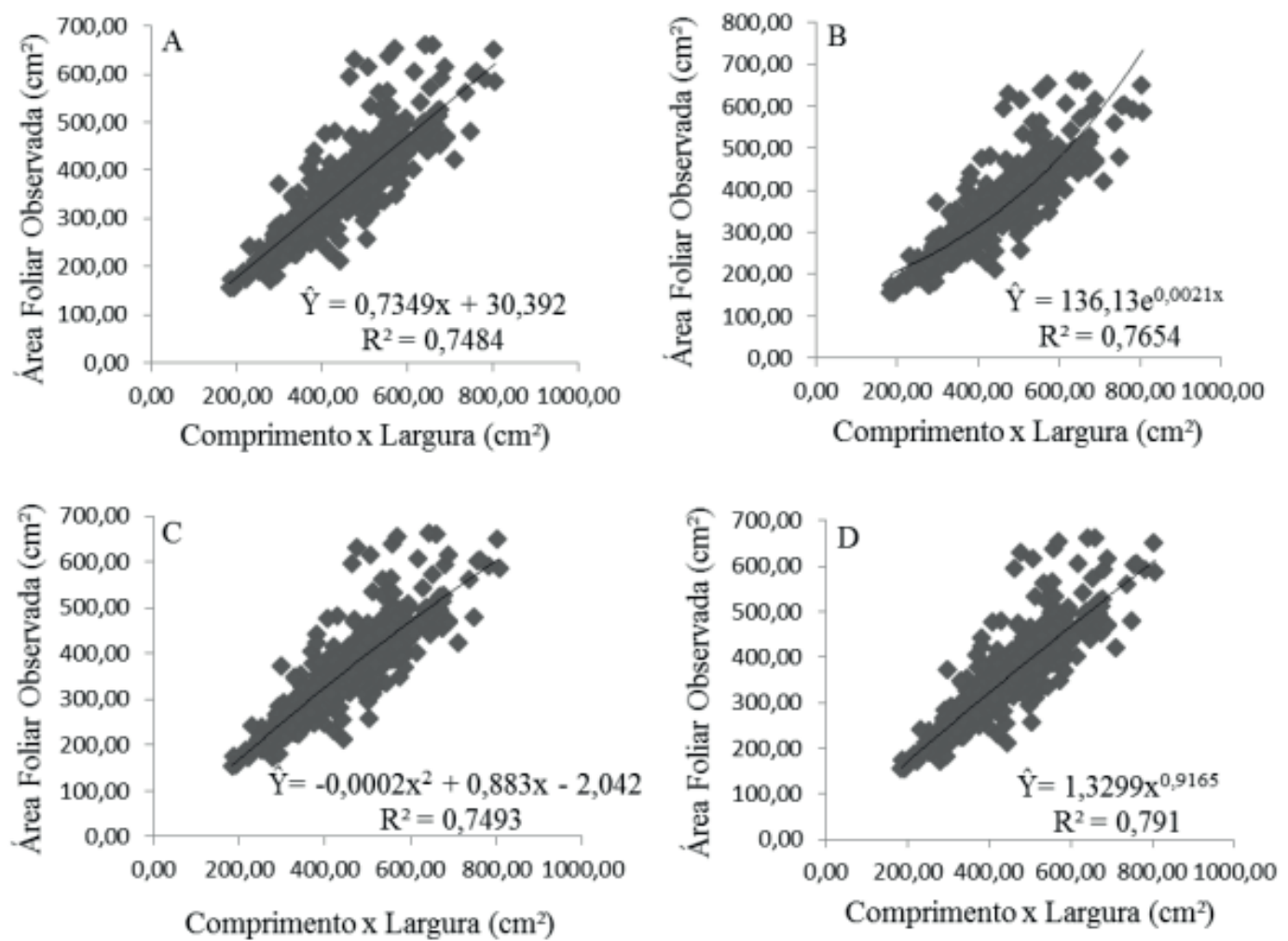

Figs. 5 A-D. Representação da área foliar de indivíduos sob baixa irradiação de Aechmea blanchetiana (Baker) L. B. Sm. A. modelo Linear; B. Exponencial; C. Quadrático; D. Potencial (D) para o produto entre comprimento e máxima largura (C.L) de folhas. Equações estimadas a partir de 500 folhas. 
Tabela 3. Equações para a determinação da área foliar, utilizando o comprimento (C), a largura (L) e o produto comprimento vezes a largura (C.L) como variáveis independentes $(\mathrm{x})$ e coeficiente de determinação $\left(\mathrm{R}^{2}\right)$, com base em 500 folhas sob baixa irradiação Aechmea blanchetiana (Baker) L. B. Sm. Os índices 1, 2 e 3 indicam comprimento, largura, comprimento x largura, respectivamente.

\begin{tabular}{lccc}
\hline Modelo & X & Equação & $\mathrm{R}^{2}$ \\
\hline Linear 1 & C & $\hat{\mathrm{Y}}=6,2361 \mathrm{x}-17,943$ & 0,5993 \\
Linear 2 & $\mathrm{L}$ & $\hat{\mathrm{Y}}=-0,4768 \mathrm{x}+806,19$ & 0,1162 \\
Linear 3 & C.L & $\hat{\mathrm{Y}}=1,1533 \mathrm{x}-158,98$ & 0,7063 \\
Exponencial 1 & C & $\hat{\mathrm{Y}}=235,27(1,009141531)^{\mathrm{x}}$ & 0,6228 \\
Exponencial 2 & $\mathrm{L}$ & $\hat{\mathrm{Y}}=127,32(1,136)^{\mathrm{x}}$ & 0,0809 \\
Exponencial 3 & C.L & $\hat{\mathrm{Y}}=187,8(1,001)^{\mathrm{x}}$ & 0,7571 \\
Quadrático 1 & C & $\hat{\mathrm{Y}}=-0,0216 \times 2+11,404 \mathrm{x}-312,6$ & 0,6059 \\
Quadrático 2 & L & $\hat{\mathrm{Y}}=-0,0013 \times 2+0,1508 \mathrm{x}+753,69$ & 0,1295 \\
Quadrático 3 & C.L & $\hat{\mathrm{Y}}=0,0007 \times 2+0,1919 \mathrm{x}+178,94$ & 0,7141 \\
Potencial 1 & C & $\hat{\mathrm{Y}}=4,34 \mathrm{x}^{1,0679}$ & 0,6595 \\
Potencial 2 & $\mathrm{L}$ & $\hat{\mathrm{Y}}=866,14 \mathrm{x}^{-0,052}$ & 0,0312 \\
Potencial 3 & C.L & $\hat{\mathrm{Y}}=0,2454 \mathrm{x}^{1,2006}$ & 0,7624 \\
\hline
\end{tabular}

ao estudarem folhas do Ananas comosus (L.) Merr. (Bromeliaceae). Nos indivíduos de A. blanchetiana sob alta irradiação o comprimento da folha é 7,2 vezes maior que a largura, enquanto que nos indivíduos sob baixa irradiação o comprimento da folha é 17,2 vezes maior que a largura.

Fonseca \& Condé (1994) estimando a área foliar de Hancornia speciosa Gomez (Apocynaceae) em condições de viveiro a pleno sol $(100 \%)$ e coberto com sombrite $(50 \%)$ obtiveram valores de coeficiente de determinação satisfatórios nas equações obtidas para as relações entre área foliar e o comprimento $(\mathrm{C})$, largura $(\mathrm{L})$ e o produto entre comprimento vezes a largura (C.L), em que o produto (C.L) apresentou melhor adequação ao modelo, sendo a equação linear a quem melhor se ajustou ao modelo. Desta forma observa-se que o produto comprimento vezes a largura diminuí o erro, se mostrando mais confiável, uma vez que se utiliza dois parâmetros.

Toebe et al. (2010) estimando a área foliar de Crambe abyssinica Hochst (Brassicaceae) em trabalho de campo obtiveram como equação mais adequada a exponencial. Busato et al. (2010) estimando a área foliar de Batateira cultivar Atlantic (Solanaceae) em campo obtiveram as equações exponencial e potencial como as mais adequadas. Silva et al. (2013) estimando a área foliar de Citrus limonia (L.) Osbeck (Rutaceae) em campo observaram que as equações exponencial, potencial e quadrática foram as mais adequadas. Hinnah et al. (2014) estimando a área foliar de Solanum melongela L. (Solanaceae) em estufa observaram que as equações potencial, quadrática e linear mostraram-se as mais adequadas, no entanto Moraes et al. (2013) estimando a área foliar com Psidiun cattleianum Sabine (Myrtaceae), Leandra autralis (Cham.) Cogn. (Melastomataceae), Sebastiana commersoniana (Baill.) L. B. Sm. e Dows (Euphorbiaceae), Miconia sellowiana Naudin (Melastomataceae) e Psychotria suterella Muell. Arg. (Rubiaceae), em estudo de mata e borda obtiveram a equação linear como a mais satisfatória para ambas as condições. Em todos os estudos listados acima as equações relacionadas com o produto entre comprimento vezes largura (C.L) foram as mais satisfatórias, corroborando com os resultados do presente estudo para ambas as condições analisadas (Tabs. 2, 3) mostrando ser eficaz para a estimativa de área foliar de muitas espécies.

Ao se fazer a validação a partir das amostras de 100 folhas de $A$. blanchetiana de indivíduos sob alta irradiação verificou-se que das 12 equações encontradas, apenas quatro se mostraram adequadas, de acordo com o critério de coeficiente linear $\beta_{0}$ estatisticamente igual a zero e o coeficiente angular $\beta_{1}$ estatisticamente igual a um (Tab. 4). Destas quatro equações que se mostraram apropriadas, três estão relacionadas com o comprimento (C), sendo o linear, quadrático e o potencial, contudo o modelo mais satisfatório entre as quatro foi quando se utilizou o produto entre o comprimento vezes a largura, sendo o modelo quadrático o mais adequado, com menores valores de erro médio $(\overline{\mathrm{E}})$, erro absoluto médio (EAM) e da raiz do quadrado médio do erro (RQME), o que segundo Schwab et al. (2014) quanto mais próximo de zero essas estatísticas estiverem, mais adequado será o modelo e o valor do índice $\mathrm{d}$ de Willmott mais próximos da unidade. O índice d é uma medida de quanto o modelo está livre de erro, quanto mais próximo de 1, menor erro apresenta esta estimativa (Willmontt 1981). Os valores do índice d variam de zero para nenhuma concordância, a um, para a concordância perfeita.

Conforme Schwab et al. (2014) quando o preditor da área foliar é o produto entre a largura e o comprimento da folha, a relação passa a ser linear, com maior coeficiente de determinação. Desta forma é mais indicado utilizar as duas dimensões da folha do que somente uma. Todavia apesar da precisão na estimativa da área foliar a partir do produto (C.L), segundo Aquino et al. (2011) há uma aumento do tempo gasto para medição destas variáveis. Segundo Maldaner et al. (2009) a utilização de apenas uma variável biométrica é mais eficaz, uma vez que reduzem pela metade o número de medições quando comparado com o produto das dimensões lineares.

Ao se fazer a validação a partir das amostras de 100 folhas de $A$. blanchetiana de indivíduos sob baixa irradiação verificou-se que das 12 equações encontradas, apenas quatro se mostraram adequadas, de acordo com o critério de coeficiente linear estatisticamente igual a zero e o coeficiente angular estatisticamente igual a um (Tab. 5). As quatro apresentaram maior coeficiente de determinação quando relacionadas à área foliar e o produto das dimensões lineares (C.L) (Tab. 5), com menores valores de erro médio (), erro absoluto médio (EAM) e da raiz do quadrado médio do erro (RQME). Dentre as quatro equações a quadrática foi que apresentou o maior índice d de Willmott (Willmontt 1981) mais próximos da unidade.

Lucena et al. (2011) utilizando o método dos discos foliares para estimar a área foliar de Malpighia emarginata DC (Malpighiaceae) obtiveram um baixo valor de coeficiente de determinação $\mathrm{R}^{2}=0,859$, contudo, Marrocos 
Tabela 4. Coeficientes linear $\left(\hat{\beta}_{0}\right)$, angular $\left(\hat{\beta}_{1}\right)$ e de determinação $\left(\mathrm{R}^{2}\right)$ obtidos na regressão ajustada entre a área foliar estimada (variável dependente) e a observada (variável independente), erro médio (E) $)$, erro absoluto médio (EAM), raiz do quadrado médio do erro (RQME) e índice d de Willmott (Willmott 1981) calculados com base nas áreas foliares estimadas e observadas, de 100 folhas sob alta irradiação de Aechmea blanchetiana (Baker) L. B. Sm.

\begin{tabular}{lccccccc}
\hline Modelos ${ }^{(1)}$ & $\hat{\beta}_{0}{ }_{(2)}$ & $\hat{\beta}_{(3)}$ & $\mathrm{r}^{2}$ & $\overline{\mathrm{E}}$ & $\mathrm{EAM}$ & $\mathrm{RQME}$ & $\mathrm{d}$ \\
\hline Linear Simples 1 & $178,36^{* *}$ & $0,5972^{* *}$ & 0,5874 & 23,7255 & 54,14 & 69,25 & 0,84 \\
Exponencial 1 & $149,68^{* *}$ & $0,6752^{* *}$ & 0,5662 & 24,9818 & 55,66 & 72,72 & 0,84 \\
Quadrático 1 & $175,35^{* *}$ & $0,6060^{* *}$ & 0,5829 & 24,12 & 54,4 & 69,77 & 0,84 \\
Potencial 1 & $169,10^{* *}$ & $0,6133^{* *}$ & 0,5845 & 20,6522 & 52,79 & 68,57 & 0,85 \\
Linear Simples 2 & $342,02^{* *}$ & $0,0392^{* *}$ & 0,0046 & 26,8136 & 94,49 & 116,68 & 0,41 \\
Exponencial 2 & $2,8074^{* *}$ & $0,0554^{* *}$ & 0,0074 & $-33,566$ & 96,51 & 120,5 & 0,44 \\
Quadrático 2 & $342,50^{* *}$ & $0,0375^{* *}$ & 0,0043 & $-26,955$ & 94,48 & 116,64 & 0,41 \\
Potencial 2 & $333,75^{* *}$ & $0,0402^{* *}$ & 0,0046 & $-34,696$ & 96,03 & 119,44 & 0,42 \\
Linear Simples 3 & $213,2080^{* *}$ & $0,4477^{* *}$ & 0,4535 & 1,2147 & 57,4175 & 74,8722 & 0,7757 \\
Exponencial 3 & $192,2526^{* *}$ & $0,4951^{* *}$ & 0,4096 & $-1,54,72$ & 60,4787 & 78,9906 & 0,7741 \\
Quadrático 3 & $214,8663^{* *}$ & $0,4194 * *$ & 0,5265 & $-8,0072$ & 56,8454 & 74,9946 & 0,9741 \\
Potencial 3 & $212,2415^{* *}$ & $0,4438^{* *}$ & 0,456 & $-1,2527$ & 57,0844 & 74,7201 & 0,7747 \\
\hline
\end{tabular}

(1) Os índices 1, 2 e 3 indicam comprimento, largura, comprimento x largura, respectivamente.

(2) ns Coeficiente linear não difere de zero, pelo teste $\mathrm{t}$, em nível de $5 \%$ de probabilidade de erro. ** Coeficiente angular difere de zero, pelo teste t, em nível de $1 \%$ de probabilidade de erro.

(3) ns Coeficiente angular não difere de um, pelo teste t, em nível de $5 \%$ de probabilidade de erro. ${ }^{* *}$ Coeficiente angular difere de um, pelo teste t, em nível de $1 \%$ de probabilidade de erro.

Tabela 5. Coeficientes linear $\left({ }_{0}\right)$, angular $\left(_{1}\right)$ e de determinação $\left(\mathrm{R}^{2}\right)$ obtidos na regressão ajustada entre a área foliar estimada (variável dependente) e a observada (variável independente), erro médio (Ē), erro absoluto médio (EAM), raiz do quadrado médio do erro (RQME) e índice d de Willmott (Willmott 1981) calculados com base nas áreas foliares estimadas e observadas, de 100 folhas sob baixa irradiação de Aechmea blanchetiana (Baker) L. B. Sm.

\begin{tabular}{lccccccc}
\hline Modelo $^{(1)}$ & $\hat{\beta}_{(2)}$ & $\hat{\beta}_{(3)}$ & $\mathrm{r}^{2}$ & $\overline{\mathrm{E}}$ & $\mathrm{EAM}$ & $\mathrm{RQME}$ & $\mathrm{d}$ \\
\hline Linear Simples 1 & $274,7584^{* *}$ & $0,5521^{* *}$ & 0,811 & $-52,798$ & 116,3 & 156,08 & 0,88 \\
Exponencial 1 & $259,6116^{* *}$ & $0,5634^{* *}$ & 0,7919 & $-59,688$ & 120,5 & 159,13 & 0,88 \\
Quadrático 1 & $262,8514^{* *}$ & $0,5637^{* *}$ & $0,79,86$ & $-56,285$ & 115,9 & 157,01 & 0,88 \\
Potencial 1 & $255,2698^{* *}$ & $0,5659^{* *}$ & 0,811 & $-62,204$ & 116,58 & 157,36 & 0,88 \\
Linear Simples 2 & $803,2010^{* *}$ & $-0,0001^{* *}$ & 0,0114 & 244,27 & 290,82 & 116,68 & 0,28 \\
Exponencial 2 & $754,8248^{* *}$ & $0,0006^{* *}$ & 0,0809 & 28,8673 & 235,24 & 282,65 & 0,12 \\
Quadrático 2 & $754,5834^{* *}$ & $0,0000^{* *}$ & 0,0117 & 23,2188 & 235,4 & 282,75 & 0,12 \\
Potencial 2 & $787,6373^{* *}$ & $-0,0018^{* *}$ & 0,0137 & 54,9335 & 240,94 & 287,64 & 0,24 \\
Linear Simples 3 & $177,7026^{* *}$ & $0,6736^{* *}$ & 0,83 & $-61,02$ & 104,209 & 139,881 & 0,9168 \\
Exponencial 3 & $182,6682^{* *}$ & $0,6737^{* *}$ & 0,8451 & $-63,27$ & 105,945 & 139,267 & 0,9166 \\
Quadrático 3 & $185,1208^{* *}$ & $0,7064^{* *}$ & 0,8498 & $-29,62$ & 95,5235 & 122,774 & 0,9842 \\
Potencial 3 & $195,3316^{* *}$ & $0,6427^{* *}$ & 0,8351 & $-65,96$ & 108,242 & 144,8 & 0,9076 \\
\hline
\end{tabular}

(1) Os índices 1, 2 e 3 indicam comprimento, largura, comprimento x largura, respectivamente.

(2) ns Coeficiente linear não difere de zero, pelo teste $\mathrm{t}$, em nível de $5 \%$ de probabilidade de erro. ${ }^{* *}$ Coeficiente angular difere de zero, pelo teste t, em nível de $1 \%$ de probabilidade de erro.

(3) ns Coeficiente angular não difere de um, pelo teste t, em nível de $5 \%$ de probabilidade de erro. ** Coeficiente angular difere de um, pelo teste t, em nível de $1 \%$ de probabilidade de erro. 
et al. 2010 utilizando o mesmo método obtiveram um coeficiente de determinação superior a 0,85 , mostrando ser um método eficiente no uso da estimativa da área foliar de Beta vulgaris L. (Chenopodiaceae). Resultados semelhantes ao de Marrocos et al. (2010) foram descritos pelos seguintes autores em estudo de campo: Souza et al. (2012) com $\mathrm{R}^{2}=0,947$ para folha de Citrullus lanatus (Thunb.) Matsun e Nakai (Cucurbitaceae), (Cunha et al. 2010) com $\mathrm{R}^{2}=0,9783$ para Crysobalanus icaco $\mathrm{L}$. (Crysobalanaceae), (Lima et al. 2012b) com $\mathrm{R}^{2}=0,9662$ para Achras sapota L. (Sapotaceae), (Carvalho et al. 2012) com $\mathrm{R}^{2}=0,9869$ para Myrciaria tenella $\mathrm{O}$. Berg (Myrtaceae) e (Lima et al. 2012a) com $\mathrm{R}^{2}=0,8614$ para Myrciaria cauliflora (Mart.) O. Berg (Myrtaceae). Diante do exposto, acredita-se que o coeficiente de determinação varia com o formato da folha de cada espécie, e que mesmo o coeficiente de determinação de A. blanchetina para folhas de indivíduos sob alta irradiação sendo superior a 0,7484 e 0,7063 para folhas de indivíduos sob baixa irradiação, mostra-se adequado.

Lima et al. (2012c) estudando folhas de Magnifera indica L. (Anacardiaceae) relataram que a ausência de polimorfismo foliar, aliado ao formato lanceolado das folhas durante todo o ciclo, justifica o fato de o produto das dimensões das folhas ser o mais adequado para a estimativa da área foliar, o que pode justificar o melhor ajuste do modelo em $A$. blanchetiana, já que a mesma apresenta folha de formato lanceolado e ausência de polimorfismo. Segundo Lucena et al. (2011) o método dos discos foliares é variável de acordo com a espécie utilizada.

A maior área foliar em indivíduos sob alta irradiação e a maior em indivíduos sob baixa irradiação é frequentemente relatado na literatura: Poggiani et al. (1992) avaliando a resposta do sombreamento em Schizolobium parahyba (Vell.) Blake (Fabaceae), Piptadenia rígida Benth. (Mimosaceae) e Albizzia lebbeck (L.) Benth. (Fabaceae), Alvarenga et al. (2003) estudaram o efeito de quatro níveis de sombreamento sobre a concentração de clorofila em Croton urucurana Baill. (Euphorbiaceae), Scalon et al. (2003) avaliaram o crescimento inicial de mudas de Bombacopsis glabra (Pasq.) A. Robyns (Malvaceae) em condição de sombreamento, Rego \& Possamai (2006) avaliaram o efeito do sombreamento sobre o teor de clorofila e crescimento inicial de Jequitibá-rosa, Dousseau et al. (2007) analisaram a influência de condições de sombreamento sobre o crescimento de Tapirira guianensis Aulb. (Anacardiaceae), Martinazzo et al. (2007) avaliaram o efeito do sombreamento sobre o crescimento inicial e teor de clorofila em Eugenia uniflora L. (Myrtaceae), Magalhães et al. (2009) avaliaram a aclimatação de mudas de acariquara à alta irradiância, Favaretto et al. (2011) estudaram as respostas das enzimas antioxidantes de espécies arbóreas sob condição de sol e sombra, Furlan (2013) avaliou o teor de pigmentos em Theoboma cacao L. (Sterculiaceae) em condições de radiação solar, Mokochinski et al. (2014) avaliaram a variação estacional do teor de clorofila em Inga marginata Willd. (Fabaceae), Sebastiana commersoniana
(Baill.) L. B. Sm e Dows e Ocotea puberula (Rich.) Nees. (Lauraceae) em condições de luminosidade.

A luminosidade teve efeito sobre as folhas de Aechmea blanchetiana, em que folhas sob baixa irradiação apresentaram os maiores valores em todos os parâmetros, exceto pela largura que foi maior em folhas sob alta irradiação, o que se explica por ser uma estratégia adaptativa em amenizar o superaquecimento interno das folhas.

\section{REFERÊNCIAS}

Alvarenga, A.A., Castro, E.M., Junior, E.C.L. \& Magalhães, M.M. 2003. Effects of different light levels on the initial growth and photosynthesis of Croton urucurana Baill. in southeastern Brazil. Revista Árvore 27(1):53-57.

Aquino, L.A., Júnior, V.C.S., Guerra, J.V.S. \& Costa, M.M. 2011. Estimativa da área foliar do girassol por método não destrutivo. Bragantia 70(4):832-836.

Araújo, E.C.E., Santos, E.P. \& Prado, C.H.B. 2005. Estimativa da área foliar da mangueira (Mangifera indica L.) cvs. tommy atkins e haden, utilizando dimensões lineares. Revista Brasileira de Fruticultura 27(2):308-309.

Bianco, S., Pitelli, R. A. \& Carvalho, L. B. 2002. Estimativa da área foliar de Cissampelos glaberrima usando dimensões lineares do limbo foliar. Planta Daninha 20(3):353-356.

Busato, C., Fontes, P.C.R., Braun, H. \& Busato, C.C.M. 2010. Estimativa da área foliar da batateira, cultivar Atlantic, utilizando dimensões lineares. Revista Ciência Agronômica 41(4):702-708.

Campos, H. 1983. Estatística experimental não-paramétrica. Escola Superior de Agricultura Luiz de Queiroz, Piracicaba. 349 p.

Campos, M.A.A. \& Uchida, T. 2002. Influência do sombreamento no crescimento de mudas de três espécies Amazônicas. Pesquisa Agropecuaria Brasileira 37(3):281-288.

Carvalho, D.R., Nasciemnto, P.G.M.L., Silva, M.G.O., Mesquita, H.C. \& Cunha, J.L.X.L. 2012. Comparação de métodos para estimativa da área foliar do Myrciaria tenella $\mathrm{O}$. Agropecuária Científica no Semi-Árido 8(4):1-6.

Cunha, J.L.X.L., Nascimento, P.G.M.L., Mesquita, H.C., Silva, M.G.O., Dombroski, J.L.D. \& Silva, I.N. 2010. Comparação de métodos de área foliar em Chrysobalanus icaco L. Agropecuária Científica no Sem-Árido 6(3):22-27.

Dousseau, S., Alvarenga, A.A., Santos, M.O. \& Arantes, L.O. 2007. Influência de diferentes condições de sombreamento sobre o crescimento de Tapirira guianensis Alb. Revista Brasileira de Biociências 5(2):477-479.

Falster, D.S. \& Westoby, M. 2003. Leaf size and angle vary widely across species: what consequences for light interception? New Phytologist 158:509-525.

Favaretto, V.F., Martinez, C.A., Soriani, H.H. \& Furriel, R.P.M. 2011 Differential responses of antioxidant enzymes in pioneer and latesuccessional tropical tree species grown under sun and shade conditions. Environmental and Experimental Botany 70(1):20-28.

Fonseca, C.E.L.A. \& Condé, R.C.A.C. 1994. Estimativa da área foliar em mudas de mangabeira (Hancornia speciosa Gom.). Pesquisa Agropecuaria Brasileira 29(4):593-599.

Francisco, J.P., Diotto, A.V., Folegatti, M.V., Silva, L.D.B. \& Piedade, S.M.S. 2014. Estimativa da área foliar do abacaxizeiro cv. Vitória por meio de relações alométricas. Revista Brasileira Fruticultura 36(2):285-293.

Forzza, R.C., Costa, A., Siqueira Filho, J.A., Martinelli, G., Monteiro, R.F., Santos-Silva, F., Saraiva, D.P., Paixão-Souza, B., Louzada, R.B. \& Versieux, L. 2015. Bromeliaceae in Lista de Espécies da Flora do Brasil. Jardim Botânico do Rio de Janeiro. Disponível em: <http://floradobrasil.jbrj.gov.br/jabot/floradobrasil/FB5768>. Acessado em: 23.10. 2015.

Furlan, L.M. 2013. Estudo morfofisiológico e anatômico de dois genótipos de cacaueiro (Theobroma cacao L.) submetidos a diferentes condições de radiação solar. Dissertação 86 f., Universidade Federal do Espírito Santo, Vitória. 
Gomes, J.M.L. \& Silva, N.N.F. 2013. Bromeliaceae das restingas do Estado do Espirito Santo, Brasil. Natureza on line 11(2):79-89.

Gonçalves, J.F.C., Santos JR.,U.M., Nina JR, A.R. \& Chevreuil, L.R. 2007. Energetic flux and performance index in copaiba (Copaifera multijuga Hayne) and mahogany (Swietenia macrophylla King) seedlings grown under two irradiance environments. Brazilian Journal of plant Physiology 19(3):171-184.

Hinnah, F.D., Heldwein, A.B., Maldaner, I.C., Loose, L.H., Lucas, D.D.P. \& Bortoluzzi, M.P. 2014. Estimativa da área foliar da berinjela em função das dimensões foliares. Bragantia 73(3):1-6.

Kanashiro, S., Ribeiro, R.C.S., Gonçalves, A.N., Dias, C.T.S. \& Jocys, T. 2007. Efeitos de diferentes concentrações de nitrogênio no crescimento de Aechmea blanchetiana (Baker) L.B. Sm. cultivada in vitro. Hoehnea 34(1):59-66.

Kottek, M.J., Grieser, C., Beck, C., Rudolf, B. \& Rubel, F. 2006. Mapa do mundo da classificação climática de Köppen-Geiger atualizado. Meteorologische Zeitschrift 15:259-263.

Lenzi, M., Mattos, J.Z. \& Orth, A.I. 2006. Variação morfológica e reprodutiva de Aechmea lindenii (E. Morren) Baker var. lindenii (Bromeliaceae). Acta Botanica Brasilica 20(2):487-500.

Lima, M.F.P., Nascimento, P.G.M.L., Silva, M.G.O., Mesquita, H.C. \& Carvalho, D.R. 2012b. Comparação de métodos de área Achras sapota L . Agropecuária Científica no Semi-Árido 8(4):37-43.

Lima, M.F.P., Paula, G.M.L., Silva, M.G.O., Mesquita, H.C. \& Cunha, J.L.X.L. 2012a. Comparação de métodos de área foliar em Myrciaria cauliflora (Mart.) O. Berg. Agropecuaria Científica no Semi-Árido 8(1):12-27.

Lima, R.T., Souza, P.J.O.P., Rodrigues, J.C. \& Lima, M.J.A. 2012 c. Modelos para estimativa da área foliar da mangueira utilizando medidas lineares. Revista brasileira fruticultura 34(4):974-980.

Lucena, R.R.M., Batista, T.M.V., Dombroski, J.L.D., Lopes, W.A.R. \& Rodrigues, G.S.O. 2011. Medição de área foliar de aceroleira. Revista Caatinga 24(2):40-45.

Magalhães, S., Marenco, R.A. \& Mendes, K.R. 2009. Aclimatação de mudas de acariquara à alta irradiância. Pesquisa Agropecuaria Brasileira 44(7):687-694.

Maldaner, I.C., Heldwein, A.B., Loose, L.H., Lucas, D.D.P., Guse, F.I. \& Bortoluzzi, M.P. 2009. Modelos de determinação não-destrutiva da área foliar em girassol. Ciência Rural 39(5):1356-1361.

Marrocos, S.T.P., Dantas, M.S.M., Dombroski, J.L.D., Lucena, R.R.M. \& Batista, T.M.V. 2010. Análise comparativa de métodos de estimativa de área foliar em beterraba. Revista Verde 5(5):140-146.

Martinazzo, E.G., Anese, S., Wandscheeer, A.C.D. \& Pastorini, L.H. 2007. Efeito do sombreamento sobre o crescimento inicial e teor de clorofila foliar de Eugenia uniflora Linn (Pitanga) - família Myrtaceae. Revista Brasileira de Biociências 5(2):162-164.

Martinelli, G. \& Moraes, M.A. 2013. Livro Vermelho da Flora Brasileira. Andrea Jakobson Estúdio: Instituto de Pesquisas Jardim Botânico do Rio de Janeiro. Rio de Janeiro. 1100p.

Mendonça, J.C., Sousa, E.F., Bernardo, S., Sugawara, M.T., Peçanha, A.L., \& Gottardo, R. D.., .Determinação do coeficiente cultural (Kc) do feijoeiro (Phaseolus vulgaris L.) em Campos dos Goytacazes, RJ. 2007. Revista Brasileira de Engenharia Agrícola e Ambiental 11(5): 471-475.

Mokochinski, F.M., Moreira, V.S., Vogel, G.F., Martinkoski, L. \& Guilhermeti, P.G.C. 2014. Variação estacional do teor de clorofila em mudas florestais sob diferentes condições de luminosidade. Revista Verde 9(3):324-330.

Monteiro, M.M., Giaretta, A., Pereira, O.J. \& Menezes, L.T.M. 2014. Composição e estrutura de uma restinga arbustiva aberta no norte do Espírito Santo e relações florísticas com formações similares no Sudeste do Brasil. Rodriguesia 65(1):61-72.

Moraes, L., Santos, R.K., Wisser, T.Z. \& Krupek, R.A. 2013. Avaliação da área foliar a partir de medidas lineares simples de cinco espécies vegetais sob diferentes condições de luminosidade. Revista Brasileira de Biociências 11(4):381-387.

Pereira, A. R., Villa Nova, N. A. \& Sediyama, R. 1997. Evapotranspiração. Fundação de Estudos Agrários Luiz de Queiroz, Universidade de São paulo (USP), Piracicaba. 70 p.

Pinto, A., C.; R., Graziano, T. T., Barbosa, J. C. \& Lasmar, F. B. 2008. Modelos para estimativa da área foliar de Curcuma alismatifolia e Curcuma zedoaria. Bragantia 67(2):549-552.

Poggiani, F., Bruni, S. \& Barbosa, E.S.Q. 1992. Efeito do sombreamento sobre o crescimento das mudas de três espécies florestais. In Anais do II Congresso Nacional sobre essencias nativas, São Paulo, p. 564-569.

Rego, G.M. \& Possamai, E. 2006. Efeito do sombreamento sobre o teor de clorofila e crescimento inicial do Jequitibá-rosa. Pesquisa Florestal Brasileira 53:179-194.

Sabbi, L.D.B.C., Ângelo, A.C. \& Boeger, M.R. 2010. Influência da luminosidade nos aspectos morfoanatômicos e fisiológicos de folhas de Schinus terebinthifolius Raddi (Anacardiaceae) implantadas em duas áreas com diferentes graus de sucessão, nas margens do Reservatório Iraí, Paraná, Brasil. Iheringia. Série Botânica 65(2):171181.

Scalon, S.P.Q., Mussury, R.M., Rigoni, M.R. \& Filho, H.S. 2003. Crescimento inicial de mudas de Bombacopsis glabra (Pasq.) A. Robyns sob condição de sombreamento. Revista Árvore 27(6):753758.

Schmildt, E.R., Amaral, J.A.T., Schmildt, O. \& Santos, J.S. 2014. Análise comparativa de equações para estimativas da área foliar em cafeeiros. Coffee Science 9(2):155-167.

Schwab, N.T., Streck, N.A., Rehbein, A., Ribeiro, B.S.M.R., Ulhmann, L.O., Langner, J.A. \& Becker, C.C. 2014. Dimensões lineares da folha e seu uso na determinação do perfil vertical foliar gladíolo. Bragantia 73(2):97-105.

Silva, R.T.L., Andrade, A.C., Oliveira, L.M., Lima, L.G.S., Oliveira, R.L.L., Melo, E.C. \& Oliveira-Neto, C.F. 2013. Estimativa da área foliar de Limoeiro-Cravo usando dimensões lineares do limbo foliar. Nucleus 10(1):91-98.

Silva F.A.S., Azevedo C.A.V. 2009. Principal Components Analysis in the Software Assistat-Statistical Attendance, in: World congress on computers in agriculture, 7. American Society of Agricultural and Biological Engineers, Reno-NV-USA.

Souza, M.S.S., Alves, S.S.V., Dombroski, J.L.D., Freitas, J.D.B. \& Aroucha, E.M.M. 2012. Comparação de métodos de mensuração de área foliar para a cultura da melancia. Pesquisa Agropecuária Tropical 42(2):241-245.

Toebe, M., Brum, B., Lopes, S.J., Filho, A.C. \& Silveira, T.R. 2010. Estimativa da área foliar de Crambe abyssinica por discos foliares e por fotos digitais. Ciência Rural 40(2):445-448.

Vieira, T.O. 2013. Plasticidade fenotípica e aclimatação de Siparuna guianensis em resposta a gradiente de luz. Dissertação 89 f., Universidade Estadual do Norte Fluminense Darcy Ribeiro, Rio de Janeiro.

Voltolini, C.H. \& Santos, M. 2011. Variações na morfoanatomia foliar de Aechmea lindenii (E. Morren) Baker var. lindenii (Bromeliaceae) sob distintas condições ambientais. Acta Botanica Brasilica 25(1):02-10.

Willmott, C.J. 1981. On the validation of models. Physical Geography. Norwich (2):184-194.

Zar, J.H. 2010. Biostatistical Analysis. Prentice Hall, New Jersey. 944 p. 